\title{
MALES DA PSIQUE NA EDUCAÇÃO: URGÊNCIA NA RELIGAÇÃO DO PENSAMENTO
}

\author{
MALES DE LA PSIQUE EN LA EDUCACIÓN: URGENCIA EN EL RE-LIGAR DEL \\ PENSAMIENTO
}

\author{
HARMS OF THE PSYCHE IN EDUCATION: URGENCY IN THINKING RE- \\ CONNECTION
}

\author{
Milagros Elena RODRÍGUEZ ${ }^{1}$ \\ Ivan FORTUNATO ${ }^{2}$
}

RESUMO: Este artigo apresenta uma discussão sobre a relação entre psiquismo, educação e seus reflexos sobre a humanidade, produzida a partir da opinião de 27 professores, os quais foram questionados sobre a necessidade vivida de repensar os processos educativos diante dos males que afetam a sociedade. Aqui, as concepções são enquadradas na teoria da complexidade, para que possamos conectar harmoniosamente o que foi separado. A investigação é realizada com o transmétodo, a análise crítica do discurso como transmétodo, além dos estatutos modernistas de investigação. Observamos: junto com os investimentos em infraestrutura escolar, a ideia de preparar melhor os professores é um consenso para amenizar os males da educação. No final, defendemos uma reforma do pensamento por meio da desconexão e reconexão que pode levar à estagnação se sua própria dinâmica não for revisada.

PALAVRAS-CHAVE: Educação. Males. Psique.

RESUMEN: Este artículo presenta una discusión sobre la relación entre la psique, la educación y sus reflexiones sobre la humanidad, producida a partir cuestionamentos a 27 maestros en que se preguntó sobre la necesidad vivida de repensar los procesos educativos frente a los males que afectan la sociedad. Aquí las concepciones están enmarcadas en la teoría de la complejidad, de manera que conectamos armoniosamente lo que fue separado. La indagción se realiza com el transmétodo el análisis crítico del discurso como transmétodos, fuera de los estatutos modernistas de investigar. Observamos: junto con las inversiones en infraestructura escolar, la idea de preparar mejor a los docentes es un consenso para paliar los males de la educación. Al final, auspiciamos por una reforma del pensamiento mediante un des-ligar y re-ligar que puede llevar al estancamiento si su propia dinámica no es revisada.

PALABRAS CLAVE: Educación. Males. Psique.

\footnotetext{
${ }^{1}$ Universidad de Oriente (UDO), Cumana - Sucre - Venezuela. Departamento de Matemática. Doutorado em Inovações Educativas (UNEFA) - Chuao e Doutorado em Patrimônio Cultural (ULAC) - Caracas. ORCID: https://orcid.org/0000-0002-0311-1705. E-mail: melenamate@hotmail.com

${ }^{2}$ Instituto Federal de São Paulo (IFSP), Itapetininga - SP - Brasil. Docente na Coordenadoria de Formação Pedagógica.Doutorado em Desenvolvimento Humano e Tecnologias (UNESP). ORCID: https://orcid.org/00000002-1870-7528. E-mail: ivanfrt@yahoo.com.br
} 
ABSTRACT: This paper presents a discussion on the relationship between psyche, education and its reflections on humanity, produced from the opinion of 27 teachers who were asked about the need to rethink the educational processes in the face of the harms that affect society. Here, the concepts are framed in the theory of complexity, so that we can harmoniously connect what has been separated. The inquiry is carried out with the transmethod, the critical analysis of discourse as transmethods, plus the modernist statutes of investigating. We note: along with investments in school infrastructure, the idea of better preparing teachers is a consensus to alleviate the harms of education. In the end, we advocate a reform of thinking through disconnection and reconnection that can lead to stagnation if its own dynamics are not revised.

KEYWORDS: Education. Harm. Psyche.

\section{Rizoma introdutório: necessidade de investigação e a análise crítica do discurso transmétodo}

[...] na Inglaterra em meados do século XVII, a alma é um princípio imortal e imaterial que pensa, sente e governa o corpo; o cérebro, por outro lado, parecia uma glândula de aparência desagradável e irritantemente inútil. Naquele momento histórico, alguém cunhou a palavra "neurologia". Thomas Willis (1621-1675), juntamente com um grupo de sábios, inaugurou uma nova era: a "era neurocêntrica" em que nos encontramos hoje, onde cérebro e mente são dois conceitos inseparáveis ${ }^{3}$ (PUNSET, 2006, p. 9).

O autor citado na epígrafe antecede a investigação da mente, e seu estudo é de primazia no ser humano: questão que foi desvalorizada por muito tempo; mas a educação da psique é fundamental para a vida. Tudo isso regido por uma complexidade que é o corpo humano. Neste artigo, apresentamos uma discussão cuidadosa sobre a relação entre a psique, a educação e suas reflexões sobre a própria humanidade. É um texto ensaístico, produzido a partir de perguntas feitas a 27 colegas professores, de vários países de língua espanhola, em que se questiona sobre a necessidade vivida de se repensar os processos educativos face aos males que afetam a nossa sociedade contemporânea. A educação não pode mais ser reduzida a processos estritamente cognitivos e, embora isso já seja reconhecido na literatura (como em Vasconcelos, 2004, por exemplo), as escolas continuam atendendo às exigências ditadas pelos exames internacionais, que medem o progresso da aprendizagem racional, portanto, de ensino.

Quando nos referimos à palavra psique, certamente as primeiras ideias são direcionadas às várias conotações do entendimento tradicional do que significa; de imediato, talvez, a referência mais comum seja aquela que se refere à mente humana. A ideia colocada na epígrafe por Punset (2006) é digna de nota: há algum tempo a ciência vem tentando explicar como o nosso cérebro tem funcionado, buscando revelar como funciona nossa psique

\footnotetext{
${ }^{3}$ Todas as citações diretas no artigo foram livremente traduzidas do original para o português.
} 
- entendida também como a nossa mente e até mesmo a nossa alma. O autor continua comentando que somos o que pensamos, nossa mente é nossa realidade e o que somos; memórias, emoções e experiências se acumulam no cérebro.

Assim, a alma ou a psique é um tecido cerebral pesando em média um quilo e meio, e isso tende a distorcer o significado dado ao cérebro e ao pensamento, assim como a psique foi permeada por disposições regularizadas pela conveniência de projetos hegemônicos; o ser humano foi, assim, desvirtuado de seu verdadeiro poder. Mas a alma não pode ser explicada simplesmente pelo funcionamento do cérebro, sem nem mesmo considerar uma complexa teia de crenças que faz parte de quase toda a humanidade. Temos, por exemplo, a comodidade de orientar a psique para a humanidade e a excelência do dia, refletindo sobre nós mesmos, nossa comunidade e todo o planeta; ou continuar ignorando tudo isso.

Na educação em geral, a conformação da psique é um assunto delicado, gerando várias questões: por que os males da humanidade estão se espalhando na educação? Como a humanidade chegou ao desenvolvimento de sua desumanidade que tanto ignora a terra-pátria? Como os males da psique se propagam na educação? Sem dúvida, a psique tem convergência para essa desumanidade dos males das civilizações.

Aqui, as concepções são esquadrinhadas pela teoria da complexidade; de maneira que conectamos harmoniosamente o que está separado na modernidade-pós-modernidadecolonialidade; pois o que acontece na psique acontece no resto do corpo e é emitido em comunicação com o espírito (ou a alma); além disso, o ser humano é uma criação complexa e misteriosa, residindo seus mistérios na ignorância do cérebro e em sua funcionalidade total embora o avanço da neurociência tenha levado a uma melhor compreensão do nosso cérebro, ainda estamos longe de compreendê-lo totalmente e, portanto, descobrir se nossa essência está de fato no plano material.

Em muitos momentos há situações claras de disposição do ser humano nas quais se vê na decisão de comparar os males da humanidade; que mau hábito comparar um mal com outro pior e decidir qual é o pior. É preciso dizer: o mal é mau e o bem é bom; consumir drogas é tão ruim quanto lançar bombas atômicas; talvez aquele que as constrói assim como quem as dispara estejam drogados com o mal. Devemos nos conscientizar dessa lavagem cerebral que a psique regulariza. Ou o mal é medido apenas pelo número de mortos?

Nesse sentido, é claro que alguém pode consumir drogas sendo vítima da sociedade em que vive; mas causar algum tipo de dano à vida ou à propriedade de outras pessoas, a decisão é individual e não social. Embora possamos entender o contexto motivador, não podemos consentir com isso. Não é o mesmo que acontece a bomba atômica? Ou é decidido 
que um mal é melhor ou pior porque vem de lideranças de esquerda ou de direita, entendendo isso do ponto de vista de um partido político? Ou mesmo de outras fontes culturais como a economia, a religião e a própria educação?

Claro que existem males que duram muito tempo, mas outros parecem passar rapidamente; ao que parece, ambos os males - as drogas e a bomba - não trazem consequências terríveis que os fazem classificar como males? Seria possível decidir entre um mal e outro? Quanto você se ama? O que você tem em sua psique? Mais: como re-ligar o pensamento para colaborar na humanização da educação? Quais são os males da educação de diferentes perspectivas de educadores de longa data em diferentes países? Existe convergência nesses males? É exatamente sobre isso que estamos lidando nesta investigação.

É urgente des-ligar, no sentido de afrouxar as amarras, de se libertar e se desprender a psique dos velhos laços de desumanidade permeados na educação. Assim, a decolonização e a decolonialidade são projetos por excelência para se ver livre da obrigação da preeminência ocidental.

Nesse des-ligar, cria-se outra maneira de investigar fora dos paradigmas reducionistas; re-ligar tem um significado especial, "re-ligar como prática emergente do pensamento filosófico transmoderno" (RODRÍGUEZ, 2019a, p. 13), re-ligar a ética da compreensão de Morin (2006a), e "compreender permite religar, unir e desunir saberes e assumir no dia a dia, na teoria e na prática, o conceito de vida como eixo articulador da educação" (GONZÁLEZ, 2017, p. 69).

Nesse sentido, o projeto hegemônico modernista-pós-moderno-colonial de regularização da psique na educação, pela conveniência de formar um cidadão diverso para atuar na transformação, não pode ser o espaço paradigmático para a realização desta investigação; é assim que "a Transmodernidade é um novo projeto de libertação para as vítimas da Modernidade, a 'outra face' oculta e negada" (DUSSEL, 1992, p. 162). Nesse caso, as vítimas ignoradas da educação, pela colonialidade das mentes, acabam consentindo com a desumanização da educação como exercício de poder que mascara a verdade. Como doutrina, parte-se do pressuposto de que o que não vem de lá é algo que jamais permitirão que entre na cientificidade da elite; a menos que entre na insurreição libertada em que se ocupa a Transmodernidade com sua decolonização planetária. É como postulou Foucault (1992, p. 27): “a doutrina vincula os indivíduos a certos tipos de enunciados e, por conseguinte, proíbe qualquer outro".

Por outro lado, a conotação de rizoma é uma antigenealogia típica das transepistemes, que são conhecimentos tradicionais, que vêm dos transmétodos; pois bem, vamos além da 
rigidez das classificações da pesquisa em ramos não comunicáveis e bem diferenciados, modernistas, coloniais e na pós-modernidade como cone da modernidade. Com o rizoma, querem mostrar que "aqui a organização não responde a nenhum modelo estrutural ou generativo" (RODRÍGUEZ, 2019b, p. 4).

Transmétodo, além dos métodos tradicionais, é um "conceito que envolve o metamétodo; constitui e postula uma ascensão no pensamento", explica Zaá (2017, p. 91). Além disso, complementa o autor: "há uma superação dos antecedentes paradigmáticos tradicionais [...] é um exercício de reflexão onde o status quo das ciências é permanentemente repensado". É assim que a introspecção vai além dos métodos tradicionais.

Portanto, perguntamos contundentemente: $\mathrm{O}$ que aconteceria se continuássemos investigando com os mesmos métodos colonizadores já caducados? Logicamente, o que está oculto na modernidade/pós-modernidade/colonialidade continuaria velado e assim continuaríamos a ver o imenso mar do conhecimento, pela janela; em vez de erguer uma planície, um arranha-céu, uma imensa varanda; ou melhor ainda, aventurar-se naquele mar de incertezas com arquipélagos de certezas, sem negar a incerteza, como diz Morin (2006b).

Sob essas premissas, cumpre-se o complexo objetivo da pesquisa: analisar os males da psique que se propagam na educação, sob a premissa de não continuar a decidir entre um mal e outro, buscando oferecer algumas contribuições de re-ligação urgente do pensamento aos atores do processo educacional. Quanto ao transmétodo de pesquisa, se trata da Análise Crítica do Discurso (ACD) que situa a análise do discurso tradicional numa perspectiva social, educacional, política e crítica, canalizando a forma como o discurso é utilizado, legitimando a resistência, a crítica e política da necessária re-ligação; a ACD "entende e define o discurso como prática social [...] e a partir dessa convicção inicia e justifica suas análises de discurso como análises sociais" (SANTANDER, 2011, p. 209).

A análise crítica do discurso como um transmétodo libertador (RODRÍGUEZ, 2020b) é sintática, semântica e pragmática (MOLERO DE CABEZA, 2003). Ataca e explora a política do discurso, atendendo à libertação e revelação de que os problemas não são apenas educacionais; mas de natureza política. Por isso, no decolonial obtemos alguma libertação que a análise crítica do discurso revela, resgatando a ideia de uma racionalidade avassaladora que oprime os indivíduos.

É claro que, na criticidade da análise do discurso, emerge a comunicação transdisciplinar da referida $\mathrm{ACD}$, o que em sua complexidade a torna transcomplexa; cabe destacar, ainda, que a ACD localiza nas representações das estruturas discursivas que representam, confirmam, legitimam, transcrevem ou desafiam as relações de abuso de poder 
ou dominação na vida dos atores do processo educativo, que são permeadas pelos males da educação, uma questão que nos métodos tradicionais não é possível. A ACD pode ser vista como uma reação aos paradigmas modernistas dominantes, caracterizados como associais ou acríticos (VAN DIJK, 2016).

A ACD, por sua própria natureza, é reconhecida como o primeiro transmétodo transcomplexo e, de acordo, com a perspectiva da decolonialidade planetária, é objetivo da transmodernidade; as estruturas teóricas das ciências associadas aos fenômenos sociais são definidas por uma perspectiva comunicacional e da linguagem e, por isso, todo pesquisador “deve criticar conceitos, elucidar termos, construir definições e [...] manejar operações de pensamento vinculadas a estruturas lógicas-linguística” (PADRÓN, 1996, p. 10). Tudo isso permeia as falas dos entrevistados a fim de esclarecer, na medida do possível, os males da educação e as apostas dos especialistas entrevistados de diferentes países; certamente veremos coincidências que vêm da dominação colonial que ainda permeia a psique dos atores educacionais.

A complexidade teórica da ACD se manifesta na quantidade de noções que podem estabelecer categorias e subcategorias, unidades de análise e variáveis; "o discurso é concebido como uma forma de ação. Então, nesse sentido, analisar o discurso que circula na sociedade é analisar uma forma de ação social" (SANTANDER, 2011, p. 210). É uma peregrinação nas análises de quem tende a re-ligar-se, des-ligando o velho pensamento na psique do que significa educar, pois a humanidade dá claros indícios da crise da educação; esse lamento continua se transmitindo na psique e continua como um vírus na desumanidade do ser humano: educando para a dominação pela intencionalidade dos projetos hegemônicos.

A ACD surge nesta pesquisa em duas fontes: as fontes dos textos consultados e nas entrevistas realizadas com especialistas em educação, em geral, de países como: Angola, México, República Dominicana, Equador, Espanha e Venezuela; os quais foram consultados sobre: em que país mora? Quais são os males da educação no seu país? Pode decidir quais desses males são os piores? Além de oferecerem contribuições para erradicar ou minimizar esses males.

$\mathrm{Na}$ sequência, interligamos os discursos de forma complexa em: Rizoma crise na educação: tudo acontece primeiro na psique; com ele a urgência de re-ligar; Rizoma ACD em entrevistas: males da psique na educação a partir de diferentes perspectivas em diferentes países; Rizoma re-ligação: a necessidade dos atores do processo educacional de re-ligar o pensamento e; Rizoma de fechamento: re-ligando constantemente o pensamento. Esperamos, 
portanto, contribuir de alguma forma para a promoção do pensamento re-ligado para a educação.

\title{
Rizoma crise na educação: tudo acontece primeiro na psique; com ele a urgência de re- ligar
}

\begin{abstract}
Desejo que a educação produza o que uma criança tem de melhor. Esse é o único meio de melhorar o mundo. A verdade nua é que nós, adultos, não conseguimos tornar o mundo melhor do que o gigantesco cortiço que é e, quando temos a pretensão de saber como deve ser criada uma criança, estamos meramente sendo tolos (NEILL, 1978, p. 34).
\end{abstract}

Excelentes palavras do autor, que levam a uma reflexão cada vez mais profunda sobre o que significa educar uma criança. Não há dúvidas de que o mundo está coberto de males, quase todos, lamentavelmente, de origem cultural. Nós, seres humanos, enfrentamos muitos males entre nós mesmos, produzindo uma sociedade globalizada bem definida na epígrafe: um gigantesco cortiço. Se há lugares de exceção, não há dúvidas de que esses lugares também enfrentam outros males; se não os da fome e da falta de saneamento, aqueles da alma que se tenta curar com medicamentos para o corpo. Parece, portanto, não haver como escapar. Ah, mas calma, pois os problemas da humanidade se resolvem com Educação.

Eis, então, que Alexander Neill, criador da célebre escola da liberdade - Summerhill toca numa questão bastante delicada, até mesmo difícil de acreditar: a educação não tem solucionado os males da sociedade, mas ao contrário, tem ajudado a potencializar os sofrimentos do mundo. Ela o faz a partir de uma ideia viciosa de que é preciso ensinar às crianças a diferença entre o certo e o errado, pois as crianças são o futuro. O problema maior, alerta o autor a partir da metáfora do mundo como cortiço, é que não sabemos distinguir o certo do errado. Temos, em vista disso, uma educação em crise, conduzindo e sendo conduzida por uma sociedade em crise. É preciso encontrar, nos dizeres de Morin (2003), uma forma de re-ligação entre a educação que ensina e o ensino da condição humana - um ser múltiplo, complexo, paradoxal que somente coexiste no mundo.

Não obstante, explica Boaventura de Souza Santos (2020), estamos cada vez mais distantes dessa re-ligação, produzindo uma sociedade na qual a prosperidade individual é a chave do sucesso e da felicidade e o outro (ou os outros) é visto sempre como um "competidor desleal" ou mesmo um "inimigo a ser vencido". A ideia neoliberal de que cada um é responsável por si prevalece, sempre.

Assim, ao invés de um mundo de diversidade e pluralidade, temos um mundo de diferenças que se torna perigoso, pois dissemina o ódio. A educação, por sua vez, resta-se 
refém desse mundo, promovendo ainda mais a diferença: os testes e seus resultados classificatórios; as escolas e universidade de prestígio concorridíssimas, fazendo com que os jovens estudantes lutem entre si por uma vaga; os currículos sempre formais voltados para os conhecimentos das ciências, porém muito pouco aos conhecimentos da vida e o respeito à diversidade etc. Dessa forma a educação, a quem se credita as fichas para diminuição dos males, acaba por fazer dessa trama complexa. Não se decoloniza, não se desmercantiliza. Lamentavelmente, como bem apontou Boaventura de Souza Santos (2020), recuperando as ideias de Paulo Freire, se a educação não promove libertação, resta-se opressora.

Com isso posto, podemos voltar ao nosso argumento inicial: o mal maior não existe, o mau é sempre mal e na educação se propagam males que levam ao desenvolvimento da desumanidade. E se não podemos hierarquizar os males, tal como nos relembra o famoso dilema do bonde proposto por Phillipa Foot, examinado extensivamente por Thomson (1985), no qual diversos cenários são apresentados para discutir moralidade a partir da suposição inicial cuja essência nos coloca diante da seguinte dúvida: matar um para salvar cinco, ou salvar um e deixar cinco morrerem?

Esse dilema apenas deixa a nu a ideia de que existem males maiores que outros, portanto, não deveríamos nos ocupar com os males menores. Essa é uma ideia perversa, pois um mal é mau; afinal, deveríamos usar o critério de quantidade para tomar essa decisão? Ou devemos nos basear em outros fatores como a relação afetiva com os envolvidos? Ou mesmo a relação entre envolvimento direto com o mal ou sua observação passiva, no qual a passividade permite aliviar a psique (algo como: não fiz o mal, portanto não fiz nenhum mal)? Tais questionamentos são complexos, complicados até, mas nos ajudam a entender melhor a proposta de que todos os males são maus e é preciso, pela educação, parar de propagar todo e qualquer mal - mesmo de forma silenciosa, escondida, por exemplo, na seleção dos "melhores" estudantes.

É imperativo e urgente, portanto, buscar uma re-ligação entre a educação e a humanidade. Como nos disse Morin (2000), educar deve pressupor, primeiro, sempre primeiro, o ensino da condição humana. É preciso "reconhecer-se em sua humanidade comum e ao mesmo tempo reconhecer a diversidade cultural inerente a tudo que é humano" (p. 47). Sem esse re-conhecimento de que estamos re-ligados pela condição humana e que essa é amplamente diversa e diferente em cada um de nós, o que temos é uma projeção dos males e suas causas - esses dizem respeito ao(s) outro(s) e não a mim.

Edgar Morin (2000) no (re)lembra de que nós - seres humanos - somos diferentes e iguais, ao mesmo tempo; unidos pela nossa humanidade, vamos nos distinguindo 
coletivamente pela cultura, pela sociedade, pela biologia; diferenciando-nos individualmente pela afetividade, pela intelectualidade, pelos sonhos e desejos; religando-nos pela espécie. Somos, portanto, muito diferentes, mas também muito semelhantes. A educação re-ligada é essa que busca compreender a unidade (a singularidade de cada um) na diversidade (a pluralidade de singularidades) e a diversidade na unidade, ou seja, o complexo que se retroalimenta: indivíduo $<>$ sociedade $<>$ espécie $<>$ indivíduo.

Se estamos des-ligados, explica Dussel (1977), é porque há uma longa história de dominação e de opressão cultural, sem muita explicação clara, obviamente, pois se trata da dominação e da opressão humana sobre seres humanos. É preciso libertar-se-nos, revelando esse sistema de dominar e oprimir - uma epifania, segundo o autor, que transcende o sistema. A educação, nomeada como sistemas pedagógicos por Dussel (1977, p. 95), tendo evoluído do "simples conselho do pai no paleolítico" para as "universidades e institutos de investigação de alta precisão tecnológica" do nosso tempo, constitui-se em um sistema. Seria então preciso, portanto, uma epifania transcendente para re-ligar a educação à humanidade.

Dussel (2016) propõe a transmodernidade como forma de re-ligação: é preciso ir além da colonização, da mercantilização e da opressão por meio de um diálogo transcultural no qual não haja nenhum resquício de assimetria. O começo é anterior à decolonização, pois se inicia na autovalorização que, por sua vez, demanda autocrítica, desconstrução e reconhecimento dos elementos identitários negados, ignorados ou mesmo extintos. Não se nega a si, reconhece-se. A epifania não acontece apenas ao revelar, mas na transcendência na promoção do diálogo multi/intercultural crítico. E não tendo Dussel $(1977 ; 2016)$ afirmado nada a respeito do papel fundamental da educação capaz de elucidar a epifania que transcende, emprestamos as palavras de Edgar Morin (2003) para expressar sua capilaridade nesse processo: "o desenvolvimento da aptidão para contextualizar e globalizar os saberes torna-se um imperativo da educação" (p. 24).

Não obstante, a educação como sistema - portanto opressor e dominante - parece longe dessa fundamental re-ligação. Morin (2003) bem expressou ao anotar que os problemas da educação se concentram em coisas do tipo mais créditos, mais conteúdos, maior rigidez, melhores notas etc. (tudo isso entendido, pela maioria das pessoas, como sinônimo de educação de qualidade). Claro que é importante revisar, com frequência, todos esses elementos, contudo, denunciou o autor: “essas modificações sozinhas não passam de reformazinhas que camuflam ainda mais a necessidade da reforma de pensamento" (p. 99).

Para ir além das reformazinhas, Morin (2003) clama para o imperativo de reformar as mentes. Afinal, como já delineamos, a mente (ou psique ou alma) guarda os aspectos mais 
basilares da humanidade, individual e coletivamente. Nela se esconde o problema da hierarquia dos males - optando pelos maiores e menores - além de legitimar o colonialismo, a opressão e a mercantilização da vida. Isso não é nada fácil, tornando-se, conforme o próprio Morin (2003) registrou: um impasse. Segundo o autor, o sistema (educacional, no caso) não se reforma transcendendo as reformazinhas, sem antes haver uma reforma da mente/psique, a qual não se reforma sem antes transcender o sistema - "essa é uma impossibilidade lógica que produz um duplo bloqueio" (MORIN, 2003, p. 99).

Esse duplo bloqueio, paradoxal, no qual uma reforma está recursivamente atrelada à outra, resiste duramente pelo hábito, pela especialização profunda dos saberes (que faz com que não se reconheça a ligação complexa entre os conhecimentos) e pela própria sociedade que reconhece na educação o fundamento para sua própria transformação, mas exige das escolas e universidades a qualidade já exposta: mais aulas, mais conteúdo, mais aprovações... tudo isso em prol da manutenção do status quo. Superar a reformazinha só se dá por meio de uma epifania, cuja transcendência, afirma Morin (2003), somente será periférica, marginal e desviante. Alguém há de começá-la.

A recivilização da humanidade, enquanto a crise é da civilização; e nela, a educação tem uma grande responsabilidade já que está estabelecida na civilização, forçada pelo pensamento da maioria de seus atores "percebendo apenas o parcelado, o fragmentário, o descontextualizado, o quantificável, sendo incapaz de qualquer concepção global e fundamental" (MORIN, 2006c, p. 272). Estar ciente disso é uma grande necessidade.

Existe, em nós, uma esperança de que esse começo seja iniciado por professores. É preciso revelar algumas coisas, conforme denunciadas por Morin (2003, p. 101). Uma delas é: “o caráter funcional do ensino leva a reduzir o professor ao funcionário"; sendo funcionário, portanto, se está a serviço do sistema. Outra coisa é: “o caráter profissional do ensino leva a reduzir o professor ao especialista", sendo especialista, dificilmente se permite re-ligar seu conhecimento à complexidade da vida. Educar para transcender é, em sua essência, uma missão, definida por Morin (2003, p. 102) como "muito elevada e difícil, uma vez que supõe, ao mesmo tempo, arte, fé e amor".

É, ao fim e ao cabo, uma missão que se torna inevitável quando se torna afetada pela epifania: não basta revelar os males da educação, é preciso transcendê-los. Estaríamos próximos dessa epifania ou a educação tende a permanecer em crise? É o que buscamos investigar ao consultar colegas que atuam na área da educação em vários países, cujas entrevistas são esmiuçadas no próximo rizoma. 


\section{Rizoma ACD em entrevistas: males da psique na educação a partir de diferentes perspectivas em diferentes países}

Eu não posso me ouvir se não ouvir as vozes do outro (RODRÍGUEZ, 2019a, p. 12).

Neste rizoma, nos voltamos às entrevistas realizadas com pesquisadores e educadores de renomada trajetória nacional e internacional, por meio de questões que contribuem para o cumprimento do objetivo complexo da pesquisa, tais como: Quais são os males da educação em seu país?, Você pode decidir qual desses males é pior? Além de suas contribuições para erradicar ou minimizar esses males. A seguir, promovemos uma análise crítica introspectiva; buscando analisar os males da psique que se propagam na educação, sob a premissa de decidir entre um mal e outro?, almejando contribuir com a re-ligação urgente do pensamento na educação.

Por meio do Google Forms ${ }^{\circledR}$, com os convites enviados por e-mail da Venezuela, foram entrevistados especialistas em educação da Angola, México, República Dominicana, Venezuela, Equador e Espanha. No total, 27 entrevistados responderam ao formulário: 14 de Angola, 6 do México, 3 da República Dominicana, 2 da Venezuela, 1 do Equador e 1 da Espanha. Quanto à pergunta: quais são os males da educação em seu país? Expressaram que existe "má qualidade da educação devido a vários fatores que são descritos a seguir: falta de infraestrutura escolar; condições inadequadas em certas escolas; baixo nível social e econômico de muitas famílias". Destes males houve uma generalização entre os entrevistados; aliado à chamada "falta de pesquisas e atualização deficiente de conhecimentos; junto com a falta de ética, a falta de identidade, a falta de responsabilidade e bom senso, a falta de empatia e a existência de uma corrupção quase sem fim”. Esses males existem até na Espanha, onde a iniquidade se apresenta como uma falha grave.

Entre as principais respostas dos entrevistados temos "aqueles que administram a educação têm mais consciência do que os alunos enfrentam, em detrimento da aprendizagem"; contudo, "os professores universitários têm uma carga horária elevada e, muitas vezes, com um número elevado de alunos", afirmam da República Dominicana, "apesar de as universidades possuírem processos de elevada automatização e terem muitos avanços nas TIC". No entanto, eles afirmam que "os gestores tendem a assediar seus professores com controles insalubres de frequência e um alto nível de desconfiança em relação às responsabilidades de seus professores". É comum entre os entrevistados que entre os males da educação em seu país, tão diversos entre eles, a educação se apresente como 
"mecânica, muito teórica, pouca crítica e baixa participação dos alunos. O pensamento crítico não é alcançado “.

$\mathrm{Na}$ parte prática do ensino, países como Venezuela e República Dominicana responderam que "há pouca literatura disponível e poucas aulas de prática laboratorial. Baixo nível acadêmico dos professores do ensino médio e deficiência nos programas". Além de existirem vários problemas como "a falta de qualidade do ensino, a desvalorização do pessoal, até a corrupção. A falta de base ou conceitos fundamentais em muitas disciplinas".

Os entrevistados responderam que há "baixo nível de profissionalização dos professores, falta de recursos nas escolas e orientação pedagógica dos professores nas salas de aula, trabalho excessivo com burocracia". Indicaram também problemas econômicos e sociais e programas de ensino inadequados, sendo isso é comum a todos, além de problemas de falta de esperança com a "política de Estado, com a própria educação, com a formação dos profissionais docentes, com a liderança que está sendo exercida, com a falta de acompanhamento, com a falta de compromisso, com a falta de ética, com as condições desumanas em que se realiza o processo formativo, com o orçamento destinado à educação, com o sistema de dominação que se instaura sob o disfarce de uma decolonização do saber, com a desvalorização da matéria docente em termos de condições de trabalho e hierarquia que trata de uma politização socialista-revolucionária do sistema" - tendo essa sido uma resposta contundente dos entrevistados da Venezuela.

$\mathrm{Na}$ Venezuela, Angola, República Dominicana e Espanha, eles responderam que entre os males da educação em seu país estão "escolas insuficientes; número reduzido de escolas com condições básicas (água, banheiros, energia, entre outros); falta de professores; existência de cidadãos fora do sistema educacional; desigualdade na distribuição das escolas urbanas (todos os subsistemas), suburbanas (algumas) e rurais (geralmente educação primária)”, associada à “desigualdade de acesso (falta de escolas, condições socioeconômicas) e baixa qualidade da educação" - esta última, enfatizada particularmente na Venezuela.

Os entrevistados responderam que existe, evidentemente, um "baixo nível de competências dos professores. Distribuição inadequada de recursos (humanos e materiais) nas escolas do país. Má formação de professores. Poucos pais envolvidos na educação de seus filhos. Pouco investimento em educação, o que condiciona a criação de melhores condições de trabalho e melhor remuneração para o professor". Essa realidade foi destacada com especial atenção na Venezuela, onde "reina o pensamento colonizado, as falsas políticas educacionais, o currículo colonizado, um perfil de saída incompatível com a entrada em um 
nível inferior, a baixa qualidade e a falta de infraestrutura"; tudo isso aliado à baixa "qualidade, formação de professores, escolas e programas específicos".

Na sequência, foi perguntado: Você pode decidir se algum desses males é pior? Vimos que há uma decisão na psique dos entrevistados por um mal ou outro; apenas duas pessoas disseram que não podiam decidir qual mal é pior que o outro, afirmando que todos são males. Alguns afirmaram que o pior mal é a falta de pesquisa, outros a "iniquidade", que "ter mais consciência que os alunos passam em vez de aprender", "não reconhecer os conhecimentos prévios do aluno. Começar do zero. Métodos indutivos raramente usados "; outros entrevistados afirmam que "a falta de salas de aula práticas, formação de professores, desvalorização do pessoal e corrupção".

Outros entrevistados concluíram que os piores males são: “orientação pedagógica inadequada dos professores" ou problemas econômicos; um entrevistado da Venezuela afirmou que "para mim todos são piores, não há um mais do que o outro, mas se fizesse questão de priorizar, diria que o pior mal de todos é o Governo que administra o Estado". Em Angola afirmou-se que os piores males são "falta de condições nas escolas, poucas orientações, falta de atualização de planos e currículos", o que coincidiu com o Equador, referindo que o "reduzido número de escolas com condições básicas (água, sanitários, energia, entre outros), a falta de professores; existência de cidadãos fora do sistema educacional; desigualdade de acesso (falta de escolas, condições socioeconômicas)" - embora esse seja um padrão marcante em entrevistados dos seguintes países: Angola, México, República Dominicana, Venezuela, Equador. Além do "nível de qualificação dos professores, baixo investimento, falta de instituições de ensino qualificadas", que são as escolhas dos piores males por parte dos entrevistados.

Vimos que é comum que os entrevistados, a partir de sua psique, decidam entre um mal ou outro, o que parece regularizar o outro como menos mal. No entanto, essa situação é analisada na re-ligação, que é um tema central no próximo rizoma, que continua conectado a este.

Quando solicitados a contribuir para erradicar ou minimizar esses males, os entrevistados responderam que seria importante "fortalecer os profissionais da educação; criar mais infraestruturas para a educação; criar condições básicas que influenciem positivamente o processo educativo; oferecer mais cursos de pós-graduação". Esses elementos foram algo comum entre os entrevistados. Além do fato de muitos terem ido propor punições para condutas antiéticas como "consciência, responsabilidade, medidas severas de sanção"; propondo o "trabalho colaborativo", além de "mais atenção dentro e fora do horário de aula, 
de forma a reduzir o número de reprovações. Às vezes, e dependendo do assunto, o número de horas extras em monitorias deveria ser quase igual ao número de aulas normais (muitas estratégias corretivas)".

Os entrevistados propõem ainda que, em termos do professorado, pode haver "indução, criatividade e crítica"; propondo "formar professores, promover cursos de formação continuada para professores". É importante a forma como expressaram na Venezuela e em Angola, entendendo que "a educação deve se tornar o fator mais importante de uma sociedade".

Os entrevistados da Venezuela e de Angola afirmaram que essa situação é bastante complicada e que o ideal seria "começar a reestruturar o ensino primário básico em geral e formar melhor os professores". Essa reestruturação seria feita para evitar a abertura de conselhos acadêmicos entre os professores dos "campi para fazer análises de práticas e fazer propostas de mudanças e inovações orientadas por professores mais preparados" para "promover a educação".

Por isso, especialmente na Venezuela e no Equador, propõem o

[...] restabelecimento dos direitos do Estado Federal Democrático. Melhores condições de trabalho para professores. Sistemas de treinamento permanente para professores e outros líderes educacionais. Melhorias nas infraestruturas educacionais. Envolvimento dos professores em sistemas de reflexão permanente sobre a sua atuação e evolução na formação dos cidadãos. Restabelecer as condições de HCM (seguro social) e outros sistemas de saúde que façam os professores se sentirem protegidos pelo trabalho que oferecem ao Estado. Elevar o sistema de remuneração por uma vida digna para os profissionais do ensino. Assistência integral para a elevação e melhoria da saúde mental do pessoal da educação. (Relato de entrevista).

$\mathrm{Na}$ Espanha, diz-se que a solução vai depender "do governo aumentar o financiamento à educação, com maior investimento no sector da educação; construção de mais escolas (principalmente nas áreas suburbanas e rurais) e melhoria das existentes". Fala-se também em "abrir concursos para a admissão de mais docentes; desenvolvimento de cursos para capacitar professores; promover cursos de formação pedagógica para todas as pessoas que não tiveram formação docente". E essa realidade está de acordo com a Venezuela, onde se recomenda “contratar bons professores universitários para formar professores e filtrar os melhores alunos para a carreira educacional".

É urgente em todos os países "elevar o nível de investimento em educação para que seja possível melhorar suas condições concretas". E um dos entrevistados afirma que "o pensamento pode ser re-ligado; des-ligando o velho exercício colonial". Além de "investir na 
educação, eliminar a corrupção em todos os níveis (de diretores de escolas ao governo federal), melhorar a gestão de recursos e oferecer cursos de preparação para professores".

Parece, então, que junto com os investimentos em infraestrutura escolar, a ideia de preparar melhor os professores é consenso entre os entrevistados para amenizar os males da educação, embora ninguém tenha explicado como fazê-lo senão com a proposta de cursos de formação. Mas, quem é o responsável por esses cursos senão os professores? Quem, então, prepara aqueles que devem preparar a humanidade para a transformação?

\section{Rizoma re-ligação: a necessidade dos atores do processo educacional de re-ligar o pensamento}

Crucial para os analistas críticos do discurso é a consciência explícita de seu papel na sociedade. Prolongando uma tradição que rejeita a possibilidade de uma ciência "livre de valores", eles argumentam que a ciência, e especialmente o discurso acadêmico, são inerentemente partes da estrutura social, pela qual são influenciados, e que ocorrem na interação social (VAN DIJK, 1999, p. 185).

Sem dúvida, a ACD como transmétodo estabelece o papel, a participação e as subjetividades dos autores na investigação; que são inerentes ao saber, como afirma o autor na epígrafe; mas quando, como no nosso caso, a ACD é considerada transmétodo, a decolonialidade, a transmodernidade, a complexidade e a transdisciplinaridade são analisadas no discurso, assim como a essência complexificadora dos autores. Por isso, agora complexificamos a fala dos entrevistados com a dos autores, sujeitos com voz, mas também vítimas do processo e agentes de mudança. $\mathrm{O}$ transmétodo permite que nós, autores, façamos relações com o que nos afeta e com o que cumprimos com rigor; porém com a sensibilidade necessária ao caso. A educação os preocupa profundamente; acreditam que os males da psique foram o germe transmitido na educação como uma herança macabra dos sistemas dominantes. Então insistem em melhorar, seja com mais investimento, com mais formação, ou ambos.

Quando voltamos às questões iniciais, tais como: os dois males - as drogas e a bomba - não trazem consequências terríveis que os fazem classificar como males? É possivel continuar a decidir entre um mal e outro? O quanto você se ama? O que você tem em sua psique? Mais: como religar o pensamento para colaborar na humanização da educação? Quais são os males da educação de diferentes perspectivas de educadores de longa data em diferentes países? Existe convergência nesses males? Passamos a complexificar nossas próprias insolvências com os entrevistados. 
Sim, porque por muito tempo propagamos males na educação até o caminho da reforma do pensamento, agora ficamos atentos às possibilidades de não continuarmos cometendo erros tão graves. Claro, prevemos que os entrevistados decidam entre um mal e outro; eles cuidam, passivamente conformados, dos males da psique. Mas nem todos vão pelo mesmo caminho. Muitos deles afirmaram que é preciso reformular a educação desde os níveis iniciais; mas, para eles, o pensamento dos atuais professores poderia ser reformado, reformar os currículos é dar novos ingredientes aos mesmos artistas da cozinha com as mesmas receitas.

Sempre que a educação é a excelência ou o mal de amanhã, as trevas ou a luz que iluminarão os caminhos ásperos dos alunos, que se transmite por milhares de gerações se as correntes não forem cortadas, erigimos com urgência a reforma do pensamento docente, independentemente de contornarmos as políticas educacionais que jogam contra nós. Sabemos da urgência dessas políticas se voltarem a favor do alunado; mas se isso não acontecer, não podemos esquecer de Paulo Freire, que alfabetizou centenas de operários, ou Nelson Mandela, que leu e leu ao longo de 20 anos de prisão, saindo para se tornar o líder da África. Esses são exemplos de pessoas ávidas por mudança, que carregam o bastão da mudança, longe de estarem em condições ideais de políticas educacionais voltadas para a humanidade.

Por isso, tomamos consciência que os males da psique se promovem na educação: o mal mais contundente é melhor... não podemos... somos inferiores... não merecemos que os Estados tratem de seres subdesenvolvidos como nós, por isso invadiram nossas terras... quero viver como no outro governo controlador porque era melhor... Tudo isso poderia ser erradicado da mente; nada disso é verdade, esses são males da psique em que acreditávamos e o sistema dominante se adequava a isso. Somos uma grande criação humana, capazes de mudar e contribuir para o mundo. Se pudermos, encontraremos o poder dentro de nós, preenchendo nossa mente, todo nosso ser, com autoestima, vamos fazer o nosso melhor, independentemente de nossas vidas estarem cheias de injustiça. Que não nos vençam os males da psique.

Precisamos buscar, como apontou Morin (2003, p. 88), uma reforma do pensamento para termos uma psique reformada e re-ligada, "que reconheça e analise as realidades que estão ao mesmo tempo em solidariedade e conflito", como a democracia, que visa dar voz a todos, mas torna-se um projeto de partidos políticos, por isso centra-se em alguns interesses; ou o capitalismo industrial que se registra como projeto de melhoria da vida humana, mas é o que promove a fome, a miséria e as guerras. Ou ainda a educação, que precisa promover um pensamento libertador do status quo, mas tende a buscar os melhores resultados em exames 
externos, obtidos com o esforço de seus alunos e de seus professores que muito bem tiveram muito boa formação. É necessário, então, buscar a reforma do pensamento; não se começa de lado nenhum, diz Morin (2003, p. 88), pois tem "seus antecedentes na cultura das humanidades, literatura, filosofia, está se preparando nas ciências" - e ainda, diríamos, na educação.

Entre algumas contribuições da urgente re-ligação do pensamento nos atores do processo educativo, é necessário nos distanciarmos de nossa formação obsoleta, buscando aliados para essa mudança. Não importa se alguns poucos decidem que podem mudar seu pequeno mundo de educação que, com o passar do tempo, transcendendo gerações, se tornará imenso - rapidamente nos lembramos do já citado Neill e sua escola Summerhill; e a revolução pedagógica iniciada por Célestin Freinet, na França, dando voz a alunos e professores sobre o processo educacional, como foi indicado em outro texto (FORTUNATO, 2016); e Paulo Freire; e Edgar Morin; e Maria Montessori; e tantas outras pessoas dando exemplos de mudança em sua própria psique e atitudes. Precisamos da resistência do pensamento que, em meio à crise da terra-pátria, ninguém poderá nos fazer acreditar que não podemos, que somos de classes mais baixas, que não temos o dom de sermos grandes pesquisadores, que as mulheres não podem transformar nossa desumanidade; sim, podemos: a libertação pode vir de dentro de nossa psique.

É preciso, nesse des-ligamento urgente, refletir sobre nossa própria prática educativa com nossos alunos. Precisamos da humildade para descobrir o quanto estamos fazendo por cada estudante, por aquele menino e aquela menina que serão médicos que cuidarão de nós no futuro amanhã, por aqueles que serão os cientistas de amanhã; e por todos os estudantes que vão fazer tão bem pelo mundo se descobrindo artistas, zeladores, motoristas, contadores... não importa, porque tudo isso é fundamental para uma humanidade livre de males. Podemos usar a tecnologia para partilhar um pouco do que conseguimos descobrir como resistência aos males: a cultura, o que fazemos com orgulho, o que somos e para onde ir, usando nossas capacidades e sensibilidade adormecidas por um “não posso!".

Então, e na mesma sintonia, vem a re-ligação, que é a re-ligação de nossas concepções psíquicas mais íntimas, da imensidão que somos; re-ligar-se com a terra, com a cultura do fazer e com as comunidades. Levar à sala de aula uma mente social, um espaço intersubjetivo de aprendizagem onde, em todos os momentos, estamos aprendendo e re-ligando o nosso amor pelos outros, ao mesmo tempo que estão extraindo o Sapere Aude: ouse usar seus próprios meios; dizendo "penso, logo sou!". Ter consciência de que somos o que pensamos e 
de que sempre devemos estar em constante re-ligação, como essência do pensamento transmoderno.

\section{Rizoma de fechamento: re-ligando constantemente o pensamento}

O lema do clássico Descartiano, penso, logo existo! cogito ergo sum; é chamado para motivar a uma mudança de pensamento em matemática; incitando-nos a deixar a preguiça mental (RODRÍGUEZ, 2020, p. 1).

Sob o lema de Descartes, queremos dizer que cumprimos o complexo objetivo de pesquisa de analisar os males da psique que se propagam na educação, sob a premissa de não continuar a decidir entre um mal e outro, trazendo algumas contribuições para a re-ligação urgente de pensamento, nos atores do processo educacional, incluindo nós, autores da pesquisa. Estamos cientes de que não tratamos de muitos males da psique; mas o que existe está em constante re-ligação; e acreditamos que podemos e queremos ser um exemplo dessa ação vital na educação.

Ao longo do artigo, discutimos os males da psique na educação e seus reflexos na sociedade com autores que buscaram se re-ligar ao pensamento e com vários colegas professores que buscam sentido nos (nossos) dilemas de educadores. Vimos que existe um consenso: eles lutam contra os males por meio da educação. A dificuldade está em reconhecer o tipo de educação que, re-ligada, nos ajude a enfrentar os males da sociedade criada na e pela própria sociedade a partir de um pensamento desarticulado. Assim, a educação que temos hoje apenas fortalece o modelo de sociedade que segrega, discrimina e espalha seus males.

Seguimos o caminho transcomplexo como forma de superar a modernidade que coloniza e subjuga as pessoas, prioriza os males e promove uma espécie de competição entre os seres, seja pela territorialidade, seja a nível individual. Ou continuamos juntos como uma espécie racional vivendo no planeta, ou continuamos a lutar contra nós mesmos e nosso próprio lugar, simplesmente esperando um desfecho desastroso - se não pelo show de luzes e sons das bombas, pelo silêncio invisível de um vírus microscópico.

Esse tema nos estimula a ir a um estado de consciência sobre os males da psique que se propagam na educação, pois com cada um deles carregamos repressão, dominação e colonização. Prevemos uma reforma do pensamento por meio de um des-ligar e re-ligar o pensamento como uma urgência do pensamento transmoderno, ou continuaremos estagnados nos males se essa dinâmica não for revisada. 
AGRADECIMENTOS: A primeira autora agradece ao Espírito Santo de Deus que nos dá a sabedoria na arte do pensamento profundo, Deus criador amado da matemática que seus filhos iluminados pelo seu amor revelam para fazer o seu trabalho nesta Terra: “Quão preciosos são também para mim, oh Deus, seus pensamentos! Quão vasta é a soma deles! Se eu contasse, seriam mais do que areia; quando acordo, ainda estou convosco" (Salmo 139: 17-18). Bênçãos a todos em nome de nosso Senhor Jesus Cristo.

\section{REFERÊNCIAS}

DUSSEL, E. Transmodernidade e interculturalidade: interpretação a partir da filosofia da libertação. Revista Sociedade e Estado, Brasília, v. 31, n. 1, p. 51-73, 2016.

DUSSEL, E. La ética de la liberación: ante el desafío de Opel, Taylor y Vatio con respuesta crítica inédita de K. -O. Apel. Ciudad de México: Universidad Autónoma del Estado de México, 1992.

DUSSEL, E. Filosofia da libertação na América Latina. São Paulo: Loyola; Piracicaba: UNIMEP, 1977.

FORTUNATO, I. 50 anos sem Célestin Freinet, 500 anos de retrocesso das práticas escolares. Journal for Educators, Teachers and Trainers, Granada, v. 7, n. 1, p. 174-181, 2016.

FOUCAULT, M. El orden del discurso. Buenos Aires: Tusquets Editores, 1992.

GONZÁLEZ, J. Teoría Educativa Transcompleja: Educación Compleja y Transdisciplinar. La Paz: Instituto Internacional de Integración Convenio Andrés Bello, 2017.

MOLERO DE CABEZA, L. El enfoque semántico pragmático en el análisis del discurso. Visión teórica actual. Lengua Americana, v. 12, p. 5-28, 2003.

MORIN, E. EI método VI: ética. Madrid: Cátedra Teorema, 2006a.

MORIN, E. EI método I: la naturaleza de la naturaleza. Madrid: Cátedra Ediciones, $2006 \mathrm{~b}$.

MORIN, E. El método V: la humanidad de la humanidad. Madrid: Ediciones Cátedra, 2006c.

MORIN, E. A cabeça bem-feita: repensar a reforma, reformar o pensamento. 8. ed. Rio de Janeiro: Bertrand Brasil, 2003.

MORIN, E. Os sete saberes necessários à educação do futuro. 2. ed. Brasília: UNESCO, 2000 .

NEILL, A. S. Um mestre contra o mundo: o fracasso que floriu numa nova escola. São Paulo: IBRASA, 1978. 
PADRÓN, J. Análisis del discurso e investigación social: temas para seminario. Caracas: Publicaciones del Decanato de Postgrado de la Universidad Nacional Experimental Simón Rodríguez, 1996.

PUNSET, E. EI alma está en el cérebro: radiográfia de la máquina de pensar. Madrid: Ediciones Aguilar, 2006.

RODRÍGUEZ, M. E. ¡Pienso, por lo tanto soy! dejando la pereza intelectual: un re-ligar que convoca a pensar matemáticamente. Revista de Educação Matemática, São Paulo, v. 17, e020044, 2020.

RODRÍGUEZ, M. E. Re-ligar como práctica emergente del pensamiento filosófico transmoderno. ORINOCO Pensamiento y Praxis, Caracas, v. 7, n. 11, p. 3-13, 2019a.

RODRÍGUEZ, M. E. Deconstrucción: un transmétodo rizomático transcomplejo en la transmodernidad. Sinergias educativas, Porto, v. 4, n. 2, p. 1-13, $2019 \mathrm{~b}$.

RODRÍGUEZ, M. E. El análisis crítico del discurso: un transmétodo rizomático transcomplejo en la transmodernidad. Visión Educativa IUNAES, v. 14, n. 31, p. 117-128, 2020 .

SANTANDER, P. Por qué y cómo hacer Análisis de Discurso. Cinta Moebio, Santiago de Chile, n. 41, p. 207-224, 2011.

SANTOS, B. S. Para alimentar la llama de la esperanza. Casa de las Américas, Havana, n. 298, p. 5-15, 2020.

THOMSON, J. J. The trolley problem. The Yale Law Journal, New Haven, n. 94, p. 1395$1415,1985$.

VAN DIJK, T. El Análisis Crítico del Discurso. Anthropos, Barcelona, v. 186, p. 23-36, 1999.

VAN DIJK, T. Análisis Crítico del Discurso. Revista Austral de Ciencias Sociales, Valdivia, v. 30, p. 203-222, 2016.

VASCONCELOS, M. S. Afetividade na escola: alternativas teóricas e práticas. Educação \& Sociedade, Campinas, v. 25, n. 87, p. 616-620, 2004.

ZAÁ, J. R. Pensamiento filosófico transcomplejo. San Joaquín de Turmero: Escriba Escuela de Escritores, 2007.

\section{Como referenciar este artigo}

RODRÍGUEZ, M. E.; FORTUNATO, I. Males da psique na educação: urgência na religação do pensamento. Revista Ibero-Americana de Estudos em Educação, Araraquara, v. 16, n. 
3, p. 1754-1773, jul./set. 2021. e-ISSN: 1982-5587. DOI: https://doi.org/10.21723/riaee.v16i3.15195

Submetido em: 05/12/2020

Revisões requeridas em: 10/01/2021

Aprovado em: $13 / 02 / 2021$

Publicado em: 01/07/2021 